Portland State University

PDXScholar

Dissertations and Theses

Dissertations and Theses

1980

\title{
Evaluative styles of clinicians in private practice
}

\author{
Daniel R. Brophy \\ Portland State University \\ Elliot M. Geller \\ Portland State University \\ Stephan L. Grove \\ Portland State University \\ Nancy E. Hedrick \\ Portland State University \\ A. Jill Nelson \\ Portland State University
}

See next page for additional authors

Follow this and additional works at: https://pdxscholar.library.pdx.edu/open_access_etds

Part of the Psychoanalysis and Psychotherapy Commons, and the Social Work Commons Let us know how access to this document benefits you.

\section{Recommended Citation}

Brophy, Daniel R.; Geller, Elliot M.; Grove, Stephan L.; Hedrick, Nancy E.; Nelson, A. Jill; and Vanelli, Babette A., "Evaluative styles of clinicians in private practice" (1980). Dissertations and Theses. Paper 3456. https://doi.org/10.15760/etd. 5340

This Thesis is brought to you for free and open access. It has been accepted for inclusion in Dissertations and Theses by an authorized administrator of PDXScholar. Please contact us if we can make this document more accessible: pdxscholar@pdx.edu. 


\section{Author}

Daniel R. Brophy, Elliot M. Geller, Stephan L. Grove, Nancy E. Hedrick, A. Jill Nelson, and Babette A. Vanelli 
EVALUATIVE STYLES OF CLINICIANS IN PRIVATE PRACTICE

by

Daniel R. Brophy

Elliot M. Geller

Stephan I. Grove

Nancy E. Hedrick

A. Jill Nelson

Babette $A$. Vanelli

A research practicum submitted in partial fulfillment of the requirements for the degree of

MASTER OF SOCIAI WORK

Portland State University

1980 
This research practicum is submitted in partial fulfillment of the requirements for Master of Social Work for Daniel $R$. Brophy, Elliot M. Geller, Stephan L. Grove, Nancy E. Hedrick, A. Jill Nelson, and Babette A. Vanelli and approved by: 


\section{ACKNOWLEDGMENTS}

The authors of this practicum would like to express their appreciation to the psychologists and social workers who participated in the research study. Without their assistance in providing personal information about private clinical practice, this practicum would not have been possible. We would further like to thank those members of the Portland State University faculty who provided valuable information as the pilot sample for the data gathering instrument.

We would like to extend our gratitude to three friends who had freely contributed their time and expertise as consultants. We offer our genuine thanks to Lynn Thompson, M.S.W., professor at P.S.U. School of Social Work, for his significant contributions to the development of the research question and the data gathering instrument; to Susan Downs, specialist in research writing, for her professional editing assistance with several sections of the practicum; and to Lowell Kuehn, Ph.D., professor of sociology at the Evergreen State College, for his expert assistance with the development of the research design and data gathering instrument as well as in the analysis of the data.

We would like to extend a special thank you to our faculty advisor, Nancy Koroloff, whose endless support and guidance throughout this research study was a consistent source of rejuvenation. 
An acknowledgments page would be incomplete without recognition of the energy and openness shared by the six members of this research team. Our combined pleasures and struggles in developing this research study created a productive, challenging and enjoyable group learning experience. As we think back on this experience, we will remember these people and their special contributions. Finally, we would like to thank one friend who helped make this practicum a reality: Kathy Grove, who spent many long hours typing the final manuscript and creating a finished product out of a sometimes confusing mass of words. 
TABLE OF CONTENTS

PAGE

ACKNOWLED
LIST OF
CHAPTER

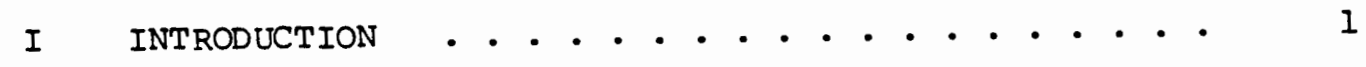

II REVIEW OF THE IITERATURE . . . . . . . . . . . . 3

Introduction ............... . . 3

Development of Evaluation in Mental Health . . 5

Group Research Design . . . . . . . . . 9

Single Client Evaluation Systems . . . . . . 12

Psychological Testing . . . . . . . . . 16

Evaluation by the client.......... . . 21

Conclusion . . . . . . . . . . . . 23

III METHODOLOGY . . . . . . . . . . . . . . 25

Research Question . . . . . . . . . . 25

Assumptions . . . . . . . . . . . . 28

Development of Instrument . . . . . . . 30

Pilot Test . . . . . . . . . . . 31

Choosing the Sample . . . . . . . . . 32

Data collection . . . . . . . . . . . 34

Problems with the Instrument . . . . . . . 35

Data Analysis . . . . . . . . . . 36 
PAGE

CHAPTER

IV ANALYSIS ................... 37

Description of the Data .......... 37

Interpretations and Implications . . . . . . 54

V CONCLUSION ................... 62

Formative and Sumative Evaluation....... 62

Techniques and Mental Processes Used ...... 63

To What Extent and in What way ........ 64

Recommendations for Future Research ...... 65

A Final Concern .............. 66

BIBLIOGRAPHY . . . . . . . . . . . . . . . 68

APPENDIX . . . . . . . . . . . . . . . . . . 75 
I Record Keeping . . . . . . . . . . . .

II Source of Information Indicating Modification of Treatment Plan ............. . . 44

III Determining How An Intervention Is Working . . . 45

IV Use of Intuitive Judgment . . . . . . . . . 47

$V$ Problems Encountered in Evaluating . . . . . . 48

VI Giving Consultation . . . . . . . . . . . 49

VII Receiving Consultation ............. . 51

VIII Influences of Consultation on Evaluation Processes 51

IX Attendance at Workshops, Seminars, Conferences . . 52 


\section{CHAPTER I}

\section{INTRODUCTION}

A belief shared by all members of the research team was that evaluation is a tool that cen be used to improve the effectiveness of clinical practice. Prompted by this interest, a research project was designed to gather descriptive data about evaluation in the private sector. The research question reads:

To what extent and in what way are licensed clinical psychologists and clinical MSW's in the private sector involved in evaluating their practice?

a. Are these clinicians using formative and/or summative evaluation?

b. What techniques and/or mental processes do they use?

After an extensive review of the literature, it became apparent that there was a dearth of information regarding the utilization of evaluation by individual clinicians. Therefore, the literature review focused upon potential evaluative tools and their development. The research question attempted to link the theoretical data base in the literature with practical application in the field. The purpose of the project was to provide an experiential data base. The sample consisted of 20 clinicians: ten licensed psychologists and ten clinical MSW's. An original instrument was developed, and a narrative summary was compiled from which interpretations and implications were developed. 
The research team was composed of six second year graduate social work students. The six members were participants in a research practicum class under the direction of Nancy Koroloff. At the outset of the project, the group members expressed a desire to learn from clinicians the value and nature of evaluation in private practice. The researchers hoped to incorporate this knowledge into their own work as professionals. A second purpose of the project was to provide information about different styles of evaluation to members of the professional community. 
CHAPTER II

\section{LITERATURE REVIEW}

\section{INTRODUCTION}

Evaluation in mental health, the systematic process of judging the worth of a program or treatment, becomes more and more important as professionals attempt to develop effective, efficient programs and treatment modalities. Through the study of both process and outcome, evaluation can assist in the gathering of information to make the decisions about what works, but also about how to improve what already is. Zusman and wurster write, ". . if properly performed, evaluation contributes to a sense of direction and development of mastery and becomes an important component of excellence" (p. 19).

Zusman, Wurster, Bloom and others consider evaluation an important research tool that supplies information necessary to make decisions and to improve services. Bloom promotes evaluation as a necessary component of a scientific practice which "permits the maximal use of the helping professional's knowledge, skills and values" (p. viii). Zusman and Wurster have identified a number of reasons for evaluation: (1) it offers to the consumer an opportunity to compare, (2) it provides impetus and information within a program for change, and (3) it provides the need for specific goals and 
objectives which are useful in themselves (p. xvii). Evaluation also offers objective measurements for change which can help remove the subjectivity of terms such as growth, change, and improvement. However, there are obstacles that make evaluation difficult. One certainly is the belief that therapy is like magic and that its effectiveness lies in its mystique. Perlman writes, "Repeatedly there has been implied the primitive fear that if we name what we know the magic will disappear from it, that if we eat of the tree of knowledge, the Eden of intuitive arts will be lost to us" (p. 54). Beyond the practical obstacles of time, money, and energy, zusman and Wurster have pointed out other obstacles that include (I) how to define measurable, but appropriate goals, (2) what percentage really indicates success, and (3) how to accurately rate the effectiveness of programs considering most evaluations indicate negative results (p. $x i x)$. Ethical considerations also present obstacles, if denying and delaying treatment in order to have control groups is a part of the evaluative designs.

A final obstacle is the actual effect of evaluation on the therapeutic relationship. The National Institute of Mental Health, in its publication Psychotherapy Change Measures, writes that professionals believe that prior evaluation can somehow diminish or alter the nature of the relationship between the therapist and client (p. 14). There is also the major issue of confidentiality. It is argued by many that confidentiality is crucial to good treatment. Freedman writes, "At the present time, in the U.S.A., there are innumerable intrusions into the psychiatrist-patient relationship, 
some necessary, others unavoidable, and some totally unwarranted" (p. 3). If evaluation is to be valued and utilized by the clinician, it must be sensitive to and protect the client's right to privacy. The research question as previously stated addresses the question: do private clinicians use evaluation in their private practice and, if so, how? Because of certain gaps in the literature, specific information in this area was limited. Therefore, the literature review will be directed toward what evaluative tools are available and how they were developed. This review will include a discussion of the historical development of evaluation, group research designs, single client evaluation systems, psychological testing, and client evaluations.

DEVELOPMENT OF EVALUATION IN MENTAL HEALTH

To give the reader a sense of background on how this field was developed, the first section will focus on the history of evaluation. The development of evaluation in mental health has been explored from two perspectives: (1) evaluative research of social issues and programs and (2) empirical research in the field of clinical psychology. Current trends will also briefly be discussed.

\section{Evaluative Research of Social Issues and Programs}

Descriptive data in mental hopsitals was collected and recovery rates were tabulated in the 1800's. Dorothea Dix (1841-1881) after visiting mental hospitals, attempted to influence the legislature to reform the treatment of mental patients. Research in public 
health between 1907 and 1927 included over 600 health surveys that gathered vital statistics on morbidity and mortality.

More formal evaluative research began in the 1900's. J. M. Rice used standardized spelling tests to relate the length of time spent on drill to spelling achievement (Caro, ed., p. 6). In the 1920's Elton Mayo and later Fritz Rowthlisberg and William Dickson did experiments on productivity and morale of industrial workers. Stuart Dodd studied the effects of health education programs on hygienic practice in syria by administering standardized pre and post tests to participants in the program. Influenced by the Depression, Chapin and his associates at the University of Minnesota did evaluative research on the effects of work relief vs. direct relief programs. He also studied the effects of treatment programs on juvenile delinquents. The concerns of the postwar era resulted in studies such as (1) experimental work on the effects of autocratic and democratic leadership styles, (2) effects of programs designed to change attitudes, and (3) evaluation of volunteer work camps.

According to Zusman and Wurster, before 1950 the primary motivation for measuring programs was curosity; only in the 1960's did the notion of accountability, "bang for the buck," begin to encourage evaluation (Zusman and wurster, p. 31). The Federal government in the 1950's and 1960's infused huge sums of money into broad social programs (Coursey, p. 2-3). At the same time, managerial systems were introduced into government beginning with the Pentagon. Cost-effectiveness as a program goal was introduced to all branches of the government when Johnson approved the Planning-Programming 
Budgeting systems. As money tightened and programs failed to achieve their promise, a more conservative philosophy used evaluation for determining accountability (Coursey, p. 2-3). Finally evaluation became mandated into law with various Congressional bills, notably the Elementary and Secondary Education Act of 1965 and the Community Mental Health Center Amendments of 1975 .

Development of Empirical Research in the Field of Clinical Psychology

The second area of development of evaluation in the mental health field, empirical research in clinical psychology, began when Wilheim Wandt in 1879 established the psychological laboratory in Leipzig, Germany (Kahn, Cameron and Giffen, p. 1-7). He applied what were for that time objective measures and utilized strict controls for his experiments. He used his findings to train others as psychologists. Ivan Pavlov experimented with methods of behavior modification; specifically in the area of classical conditioning. He measured the connection between stimulus and response and demonstrated the use of objective experimental designs. Lightner Witmer, a student of wandt, adapted his laboratory training and techniques to a clinical setting that was designed to assess and treat emotional disorders in children. John Watson, also a strong advocate of objective experimentation, stressed prediction and control of behavior through rigorous objective methodology. He started the behavior modification movement in the United States, which found support from other professionals, such as E. L. Thorndike, who did research in the area of learning, and B. F. Skinner, who was a proponent of operant conditioning. 
Sir Frances Galton helped develop measurement tools by applying psychological techniques to the study of individual differences in human behavior (Kahn, Cameron and Giffen, p. 4). Alfred Binet, however, made the major contribution to the study of individual differences, especially intelligence. He and Theodore simon were commissioned by the Ministry of Education to develop tests to distinquish normal children from the retarded. Tests he designed in 1905, 1908, and 1911 to measure mental functions revolutionized psychological testing. Revisions in Binet's measurements were made most prominently by Terman whose revision, the stanford-Binet, is a standard intelligence measurement used today.

World War I created a need for mass testing of adults (Kahn, Cameron and Giffen, p. 5). The American Psychological Association was asked to produce measures to meet the needs of the service. After World war I, ability testing was expanded to institutional settings. Personality assessment received special attention from Robert Woodworth, S. W. Pressey, Gordon Allport and L. L. Thurstone, among others. Of particular importance was the development in the 1930's of the Minnesota Multiphasic Personality Inventory, MMPI, by J. C. Mckinley and S. R. Hathaway.

As American psychologists emphasized more objective tests, their European counterparts favored associative techniques such as the Rorschach (Kahn, Cameron, and Giffen, p. 6-7). Freud himself rejected the need for statistical data and relied instead on the therapist's observations and associative techniques (NIMH, P. 70). It was not until the 1930's that the Rorschach was introduced to 
the United States by Levy and Beck. Since that time other associative methods utilizing projection have been developed.

\section{Current Trends}

Today changes are occurring in the areas of evaluative and empirical research in the field of mental health. Patton, Davis, Cox and others stress the need for utilization--how to assist administrators and clinicians in using evaluation results and how to gear the evaluation to the needs of the program or treatment. As the demand for accountability and utilization increase, traditional models of research in the mental health field are also beginning to shift to include not only testing, control groups and strict empirical designs, but also a wider range of approaches such as goal attainment scaling and record-keeping systems.

\section{GROUP RESEARCH DESIGN}

In this section as well as those following, the authors will enumerate and describe specific evaluative tools available to clinicians. In this section, the focus will be on group research design, a tool or mode of research of long standing in the social science field. One kind of group design has been the experimental approach (derived from the field of experimental psychology). Such a design most often includes a treatment and control group, a control of certain variables, and measurement of change on a periodic or pre- and post-basis. standardized tests, such as the MMPI, are frequently used. This experimental approach is the most often cited and most rigorous kind 
of research in use in the mental health field. Another research design in common use is the cross-sectional survey. Such a survey is often conducted across a population (without a control group), measurement often occurs at only one time, and the instrument may be standardized or developed specifically for the survey in question (Forcese and Richer, p. 90-106). Of course, some research occurs which combines aspects of both prototypes. There are numerous evaluative studies of casework and psychotherapy using group research design, such as Fischer (1970, p. 5-20), Kiesler (p. 49-66), Bergin (p. 230-251), and Bednar and Lawlis (p. 815-817).

Group research design is often the evaluative tool of choice. It is appropriate for assessing group work treatment; it presents within group averages or statistical distributions and can indicate, for example, what percentage of the clients improved and/or to what degree such improvement occurred under the treatment in question (Chassans, p. 107). Group research design has been and is currently used to standardize psychological tests and thus helps researchers make more precise definitions of normative behavior. Group design is relied on heavily to provide necessary accountability and related program evaluation data.

However, there are definite limitations in group design. First of all, it is not as useful to the clinician as other forms of evaluation because it often cannot give feedback on the effect of treatment on the individual client. Chassans explains why this happens:

It follows that 1) because of the extent of variation between patients in many characteristics which may be relevant to the success of any given treatment, and 2) 
as a consequence of the conclusion that a statistically significant difference between groups can occur as a result of effectiveness in only a very few patients in the study, and 3) because the method is not capable of specifying the particular patients involved, results from an extensive study [i.e., group design] yield relatively little information... for the selection of a treatment for a given patient . . . (p. 174; also see Bloom, p. 179 and Bednar and Lawlis, p. 815).

Kiesler also looks at group research design critically. He states that often such research has a sample group with a wide range of diagnoses and an outcome measure of overall patient improvement; such a "generalist" orientation can only "lead to predominantly meaningless results and perpetuate confusion" (p. 40). Fischer points out that the vast amounts of money spent in group research design or program evaluation have not really paid off: they have shown the ineffectiveness of many caseworker activities, but they have not really facilitated technique building and technique validation in practice with individuals (p. 88-89, 1978). Group research can be impractical: it can be costly, time-consuming, and inappropriate for evaluating therapy based on individual treatment plans.

It should be noted that Kiesler has suggested a "grid model" or "factorial design," a group design where some of the deficiencies mentional above are minimized (p. 41), First, he proposes that group research should be done with homogenous groups. Next, uniform outcome should not be expected; specifics should be hypothesized about the expectations in terms of the client's directionality of and/or degree of change on the same or different dimensions. Further, therapist personality type and behavior repertoire should also be 
matched to patient group. Through such a design more information about individual effect could be gathered.

Group research design has been an evaluative tool relied on traditionally by clinicians and their agencies. It is still heavily used; improved design models may help foster continued usage. Nonetheless, other forms of evaluation, such as periodic record keeping and single subject design, are often more practical and provide more specific information to the practitioner.

\section{SINGLE CLIENT EVALUATION SYSTEMS}

There are two kinds of evaluative procedures that enable a practitioner to track an individual client's progress: record keeping and single subject design. Under the record keeping umbrella, one finds such systems as process recording, POMR, and GORK. Refinement of single subject design has led to related systems such as goal attainment scaling.

Record Keeping

This discussion will cover different recording styles currently in use as well as focus on how record keeping relates to evaluation issues.

Timms indicates that prior to the 1930's, records usually consisted of simple, brief entries done in a bookkeeping or diary fashion (p. 7-15). Process recording became popular during the $1930^{\prime} \mathrm{s}$; such recording "Attempts to present an account of the interaction between social worker and client as this develops in the course of an interview" (p. 15). The popularity of process recording 
was in part due to the influence of the psychiatric and psychoanalytic practices on social work. In current times recording seems to be done in a compromise fashion with some summary and some process recording. The Social Work Encyclopedia presents similar information on recording; it names three types of recording in use since 1940-chronological, process, and summary. It notes that taping and video have come more into use during this decade (p. 1161-1168). Computer systems are also increasingly important, especially in storing abbreviated records on clients.

The record of worker-client transactions can aid the clinician, supervisor, or agency in reflecting upon, evaluating, and improving practice. Timms elaborates upon this idea: recording can serve to advance standards, appraise movement or change, aid memory and thus facilitate orderly thinking and practice effectiveness (p. 23-44). Nicholds adds similar reasons such as indicating the basis for agency participation, showing how agency responsibility was met, providing diagnostic information leading to treatment formulation, serving as a learning tool for the caseworker, and providing a basis for service evaluation (p. 36).

From the above, one can see that most reasons for recording touch upon evaluation issues; nonetheless, record keeping is definitely a less than perfect evaluative tool. The imprecise and informal format of most records often makes exact evaluation judgments difficult. Consequently, some writers have suggested that standardization of recording format is necessary and will aid the clinician in better evaluating his own work and facilitate more accurate 
program evaluation. One standardized format that has become popular, in medical as well as nonmedical settings, is the Problem oriented Medical Record (POMR).

The Problem oriented Medical Record (POMR), a major contribution to record-keeping systems, originated in the medical field. It grew from the concerns of such doctors as Lawrence Weed and Frank Curran that medical records needed to be standardized in an orderly fashion based on the scientific method (Weed, p. v-x). The literature indicates that the POMR has helped improve quality of care; also the system lends itself to computer analysis, auditing and accountability reviews (Shaughnessy and Burnett, p. 160-161). The POMR is broken down into four basic areas: (1) Data Base, (2) Problem List, (3) Initial, and (4) Progress Notes (Weed, p. 13). The POMR and a component of it, the progress note based on the subject objective Assessment Plan (SOAP) format, have influenced and been copied by many private clinicians. The SOAP parts can be broken down even further.

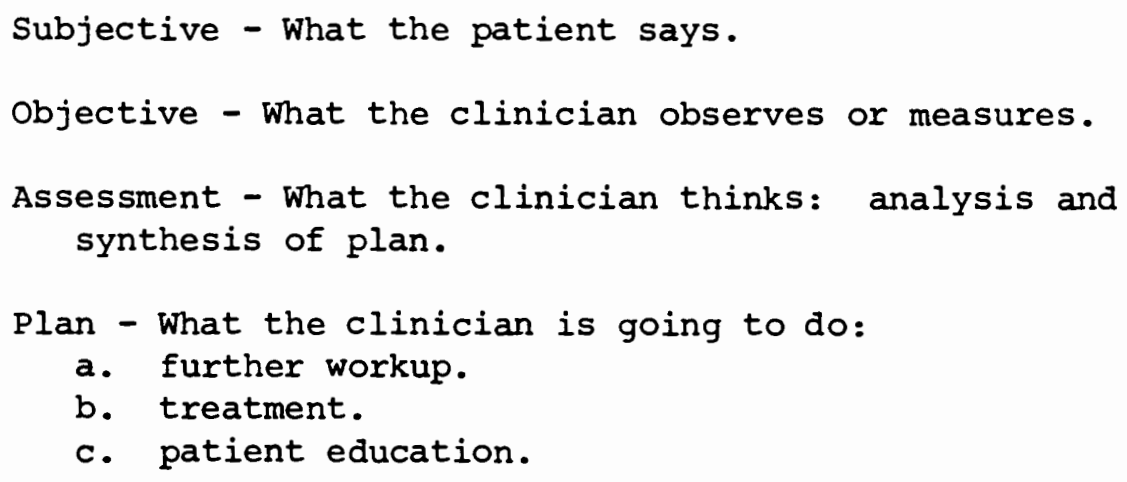

In some agencies the traditional POMR version is implemented without the use of SOAP. Yet in other agencies only the SOAP format is used. 
Because of the advantages of POMR and SOAP in medical record keeping and because of the similarity between the medical treatment process and other treatment modalities, these systems have been adapted by other fields such as psychology and social work. One adaptation is the Problem Oriented Record Keeping (PORK) system. This system was developed to be used with the social, psychological and emotional elements of the client's life. Unlike POMR, PORK may be carried out by one person, such as a therapist, rather than by a treatment team which is usually used for the POMR system; this has made it very applicable for use by private practitioners and clinicians.

\section{Single Subject Design and Related Systems}

Single subject design tracks, on a quantitative basis, the individual's progress. This in part comes out of the development of behavior modification theory. It is conducive to treatment in individual therapy as it allows the therapist to pinpoint exact problems, develop treatment plans, and monitor exact degrees of changes. This design consists of determining baseline behavior, applying intervention, charting changes in problem behavior, and evaluating the success of treatment. Martin Bloom and other social workers have applied this evaluation process. He has labelled his version of single subject design as the Problem Oriented Evaluation Procedure (PEP).

A variation of the single subject design is Goal Attainment Scaling (GAS) which was developed by Thomas J. Kiresuk and 
Robert E. Sherman during the mid-1960's as a way of evaluating and setting goals for single subjects in therapy (Clarkson, Koroloff, Newberger and Ines, p. 6). Where single subject design has been often tied to behavior modification therapy, GAS is meant to be adapted to any treatment method or style. This system is controversial as it is more subjective in nature than traditional single subject design tools in that it does not use baseline data nor necessarily quantify client change.

Since GAS is a tool for evalution, a comparable recording system needed to be developed. This system was the Goal oriented Record Keeping (GORK) system. It is like the PORK system, but instead of using a format like SOAP to determine treatment success and progress, a goal structure is used to keep clients and practitioners on task and allow evaluation of service upon termination (J.C.H., p. 1-17). A version similar to the GORK is used at agencies such as oregon State Children's Services Division.

\section{PSYCHOLOGICAL TESTING}

Both group design and single client systems often rely on psychological testing as it is another way of assessing/diagnosing and measuring change in the presenting problem. These tests offer the clinician a tool that can be a time saver in collecting information. They can tap areas in a comprehensive fashion and, through the use of norms, they can assist the clinician in judging the severity of a problem. Psychological tests measure a person's psychological state, 
including intelligence, personality and thinking processes. The selection of specific measurements is determined by the clinician, based on academic training, professional experience, and the client's needs. There are generally two types of psychological tests: impressionistic-projective tests which are sensitive to non-verbal as well as verbal communications and (2) actuarial tests which require paper and pencil (Kahn, Cameron and Giffen, p. 19). The Seventh Mental Measurement Yearbook has listed 5,426 tests and techniques including tests for achievement, aptitude, intelligence, mood states, personality, and diseases of the brain and nervous system.

Psychological tests have two functions: (1) assessment/ diagnosis and (2) measuring change. These areas are not rigid categories, and some tests can be appropriate in both areas. The following discussion about testing comes primarily from Kahn, Cameron and Giffen's book Methods and Evaluation in Clinical and Counseling Psychology.

\section{$\underline{\text { Assessment/Diagnosis }}$}

Assessment is the first logical step in an evaluation plan and provides direction for treatment. Perhaps the most well-known tests for intelligence are the Stanford-Binet Intelligence scale and the Wechsler Scales that include the Wechsler Adult Intelligence Scale, the Wechsler Intelligence Scale for Children, the revised version (WISC-R), and the Wechsler Preschool and Primary Scale of Intelligence. They measure both verbal and performance tasks and are broken down into subtests, going from simple to difficult tasks. Because of 
increasing concern about cultural bias, other intelligence tests have been developed that attempt to be culture free such as the Ieiter International Performance Scale, and the Culture Fair Intelligence Test.

A number of tests assess psychological pathologies, one of the most popular being the Minnesota Multiphasic Personality Inventory, MMPI. It is a paper and pencil self-report questionnaire, scored with controlled standardized procedures. Through a patterned analysis that utilizes a combination of scales, this test can assist the clinician in diagnosing character disorders, neuroses, and psychoses. It should not be used as a single psychometric indicator, but rather with other assessment measures.

Other tests such as the Rorscharch, the Thematic Apperception Test, and the Draw-A-Person Test, all assess psychological pathologies through impressionistic-projective techniques. By utilizing a series of cards, the clinician using the Rorscharch observes and records a client's verbal and nonverbal responses. Interpretations are then made from the client's responses. The Thematic Apperception Test, TAT, also elicits projections from cards. In the past, every sentence was carefully analyzed for pressures in the client's life, etc., but the TAT can more appropriately help to identify major themes in a client's life. It should not be used as a diagnostic tool for neuroses, psychoses, etc. (Kahn, Cameron and Giffen, p. 99). In the Draw-APerson Test interpretations are made not only on the finished product, but also on the process the client went through to draw the picture. 
Tests to determine brain damage include the Hunt-Minnesota Test, the Bender Motor Gestalt Test, and the Benton Revised Visual Retention Test. The Hunt-Minnesota Test of Organic Brain Damage tests recall of words, design and numbers (recent memory), and matches this performance against previous information. The Bender Motor Gestalt Test, a popular inclusion in an organic battery, requires the client to reproduce eight geometric design. The Benton Revised Visual Test relies exclusively on the client's ability to use visual memory effectively.

\section{Tests for Measuring Change}

The second area of testing in psychotherapy is for measuring change. These tests are used not only for outcome evaluation, but also as part of the assessment process and a guide during treatment. These tests include the California Psychological Inventory, the Hopkins Symptom Checklist, the S-R Inventory of Anxiousness, and a series of instruments developed by Hudson and associates. The California Psychological Inventory has 480 true-false items, scored for favorable personality traits such as sociability, self-acceptance, responsibility, and self-control. The Hopkins symptom Checklist is a short selfreport test that is then factor analyzed into five areas: somatization, irascibility obsessive, compulsive rumination, depression, and anxiety. The S-R Inventory of Anxiousness is useful for treatment aimed at reducing fear, anxiety and phobia. The client is asked to respond to a described situation from a set of responses on a five point scale. The Hudson instrument is designed to assist the clinician 
in assessing the client's problem and to provide continual feedback during treatment. It is a series of short, easy to administer instruments that cover problem areas such as marital problems, selfesteem, sexual problems, and depression. These 25 items tests are usually administered every other week and indicate change within the client (Fischer 1978, p. 108-116).

The value of psychological testing is continually debated. Writers such as Kahn, Cameron and Giffen support the value of testing when standards have been met for validity, reliability and useability (Kahn, Cameron and Giffen, p. 19-31). Others argue that psychological tests are not effective means of assessing problems or evaluating treatment. The Psychotherapy Change Measures published by NIMH argues that "the picture that emerges from the review is one of discouragement concerning the usefulness of psychological tests on evaluating outcome in psychotherapy" (NIMH, p. 37). Tests such as the CPI "provide a redundant, inefficient and confused picture of a person" (Kahn, Cameron and Giffen, p. 34). How accurate an assessment can a clinician get by having a client answer a set of questions? How reliable are self-report type measures? Do intelligence tests truly measure an individual's intelligence or is the test really measuring intelligence based on a white, middle class standard? other arguments claim that impressionistic-projective tests such as the Rorscharch are too subjective and based almost completely on the clinician's own interpretation.

Psychological testing has the potential to assist the clinician in private practice to assess and measure change in their treatment. 
There are a wide variety of tests available varying in degree of objectivity and degree of acceptance within the helping profession.

\section{EVALUATION BY THE CLIENT}

Another evaluative option that practitioners can tap is the feedback clients can provide on how they view therapy, its process and outcome. The discussion here will cover how such client involvement was considered inappropriate in the past and will look at the benefits and drawbacks of the client evaluation procedures as they are used today.

In past years, client feedback was seldom asked for because clinicians generally believed that their status as professionals precluded evaluation or criticism by their clients. This occurred in part because psychiatry perpetuated and influenced social work with the notion that the patient's view is likely to be distorted (Giordano, p. 34). Nonetheless, the pendulum of opinion about client input is beginning to swing in the opposite direction. For example, Fischer notes that the term "client" is used more today than the earlier term "patient"; he describes how this connotes a new peer relationship:

Clients would not be viewed as sick or defective, but as people with problems in living . . Much as phenamenological approaches. . aver that the only reality for people is their own reality, so would this view of clients. . replace the traditional use of secret labeling ("pseudoneurotic schizophrenic") with a focus on the clients' own perceptions ( $p .14,1978$ ).

Giordano lists some of the benefits of client evaluative involvement (p. 34-37). First, such involvement can help improve organization- 
client relations and facilitate attainment of organizational goals. Also Giordano indicates that client feedback is invaluable in areas where the sought changes are hard to measure, such as changes in self-image or family relationships. Furthermore, client evaluation probably has no more bias than the more traditional approach of asking agency personnel to assess their own effectiveness. Lastly, this author notes that many clients cannot relate to the style of the social worker assigned to them while simultaneously social workers often experience similar feelings toward the client; in such situations, ongoing evaluation may prevent therapy from ending in an abortive fashion (p. 34-37).

Various authors describe client self-reporting--that is, when a client monitors everyday behavior and reports back to the practitioner-and point out its drawbacks. One drawback Howe discusses is questionable reliability and possible reactive bias: that is, the mere act of recording the behavior, changes it (p. 29). Ho states that heavy client feedback may not be feasible with inarticulate clients; seeking client input may also be difficult with involuntary clients or with clients who believe the therapist should provide all the direction (p. 26). Some techniques can be used to minimize the problems inherent in the client evaluation approach: have the practitioner spot check the validity of the client report, have the client report behaviors rather than thoughts or feelings, make the reporting instrument simple and concise, and stress to the client the importance of reporting accurately regardless of whether or not the data collected relates positively to therapeutic goals (Howe, p. 31). 
The literature presents various proposals about the future use of client input. Ho asserts that it is more appropriate, at the beginning of or during treatment, to rely on the client's statement about the problem rather than standardized tests. The latter are not individual-specific but rather relate to global mental health concepts; they do not reflect cultural and ethnic background, nor do they give information about present social environment. He has designed the Practice outcome Inventory; using this, the client and practitioner formulate behavioral "descriptors" of the problems, and then the client rates himself in relationship to these descriptors during therapy to see if goals are being met (p. 24-27). His inventory procedure is similar to contracting techniques. Giordano makes suggestions about how to construct a questionnaire tapping client evaluation of outcome. First, the client should be involved in constructing the outcome questionnaire. Also, it is essential that such a survey ask about the contrast between his initial expectations and desires and the help the client actually received (p. 34-39) .

\section{CONCLUSION}

From exploring the information available in the literature, the authors have discerned these categories of evaluative tools: (1) group design, (2) record keeping, (3) single subject design and related systems such as GAS, (4) psychological testing, and (5) client evaluation. Now with the research study, the aim will be to find out 
whether therapists are evaluating their work and, if so, whether therapists are using the techniques covered in the prior review or ones not yet discussed. 
CHAPTER III

METHODOLOGY

RESEARCH QUESTION

The research question evolved in a series of stages. The broad topic suggested to the researchers by their faculty advisor at the outset of the project was "How do clinicians evaluate their success with individual clients?" After consideration of the many directions exploration of this question could take, the research group decided to concentrate upon two areas: how clinicians evaluate their work and what techniques they use.

At this point, the researchers consulted with faculty members for assistance in further defining the areas of interest. Lynn Thompson, MSW, PSU School of Social Work, suggested that there were three issues that needed to be addressed: first, how much evaluation is done; second, what kind of evaluation is done (i.e., formative and/or sumative evaluation); and finally, what techniques are being used.

Utilizing these three questions as a guide, the group formulated the research question. The final question reads:

To what extent and in what way are licensed clinical psychologists and clinical MSW's in the private sector involved in evaluating their practice? 
a. Are these clinicians using formative and/or summative evaluation?

b. What techniques and/or mental processes do they use?

The next task was to operationally define the key terms in the research question. These definitions, coupled with the assumptions upon which the project was based, served as a framework for the data analysis.

Evaluation is defined as the systematic process of judging the worth of a program or treatment. The purposes of evaluation are to determine the effectiveness in meeting goals and to contribute to decision making.

Two kinds of evaluation used in clinical practice were specified in the research question. Formative evaluation is that in which goal attainment is assessed at regular intervals in order to shape and influence the direction of the treatment process and the growth of the client. The intent is to improve on the effects of current treatment practices (e.g., to modify the treatment plan or to alter intervention techniques). Summative evaluation is that in which goal attainment is assessed only once in order to determine the overall value of a particular treatment method. The intent is to obtain information for major decision making (e.g., to terminate treatment).

Another key term in the research question is "extent." For the purposes of this project, extent is defined as the space which evaluation occupies within a clinician's work frame. The objective here was to determine how much of a priority clinicians place upon evaluation rather than to obtain a numerical estimate of actual hours spent in evaluative activities. 
Intuitive judgment, techniques, and mental processes are the final three terms to be defined. "Intuitive judgment" is not a term directly from the research question. However, all clinicians in the sample were asked a specific question regarding intuitive judgment and the researchers felt that it was necessary to define the concept. The Myer-Biggs Type Indicator, an instrument used to determine personality type, defines intuition as an immediate awareness of the whole configuration without a real comprehension of the details. The researchers expanded upon this definition to make it more applicable to the therapeutic relationship. Intuitive judgment is defined as a subjective evaluation based upon individual perception. Essentially, it is a "gut level" reaction to the verbal and nonverbal communication that occurs during a therapist-client interaction.

A technique is a method or technical skill used to accomplish a desired aim. In the current study, techniques are specific activities used by clinicians for evaluative purposes.

Mental processes are internal, intellectual activities undertaken to bring about a desired result. The focus in the research project is upon the mental processes used for evaluative purposes. The distinction between techniques and mental processes is that techniques are concrete activities whereas mental processes are more abstract in nature. 


\section{ASSUMPTIONS}

Several assumptions served as the basis for decisions made throughout the project regarding development and application of the instrument and data analysis. The assumptions will be enumerated here and referred to throughout the paper when applicable.

Two sets of assumptions were developed by the researchers. The first set includes the basic tenets underlying the project. These general statements represent values and beliefs shared by the research group. The second set of assumptions includes specific statements that were designed to serve as a framework for the data analysis. The researchers will attempt to validate or invalidate these assumptions in the description and interpretation of the data.

It should be noted that the assumptions evolved over the first few months of the research project. The value statements emerged as a result of group discussions at the outset of the project regarding the purpose and goals of the research. Many of the more specific assumptions were developed simultaneously with the research question. Finally, information obtained from the pilot sample was utilized for further clarification of the premises upon which the project was based.

The first set of assumptions includes three statements:

1. It was assumed that clinicians want to improve the effectiveness of their practice.

2. It was assumed that evaluation is a tool that can be used to improve the effectiveness of clinical practice.

3. It was assumed that clinicians may be engaged in evaluation of their practice whether or not they recognized the process as evaluative. 
Seven areas of concern comprise the second set of assumptions.

1. It was assumed that the researchers would be able to describe the extent to which clinicians do evaluate.

2. It was assumed that evaluative information could be obtained by analyzing techniques currently used by the clinicians.

3. It was assumed that clinicians have a working familiarity with various evaluative procedures which would have an impact upon their current practice. such knowledge could come from four areas: graduate school training, professional experience prior to and/or during private practice, research experience, and contact with other professionals in the social service network (e.g., consultation, workshops, conferences).

4. It was assumed that the theoretical orientation and discipline of the clinician would influence the utilization and nature of evaluation procedures. There were two issues involved here. First, the researchers believed that those clinicians with a behavioral orientation would be more likely to use single subject designs, or variations thereof, than those clinicians with a psychoanalytic orientation. Second, the researchers believed that, due to extensive training in the use of tests, psychologists would use more formal testing procedures than social workers.

5. It was assumed that time and money would put some constraints upon the use of evaluation in private practice. The crucial variable here would be the value the clinician placed on evaluation.

6. It was assumed that the more involved clinicians were in activities outside their private practice (e.g., consultation, workshops, training), the more likley that these individuals would engage in evaluation of their practice. The assumption was based on the belief that frequent contact with other professionals would expand the clinicians' awareness of evaluation, and, therefore, increase the likelihood that they would incorporate evaluation techniques into their practice.

7. It was assumed that the record keeping process utilized by clinicians would be one indicator of their evaluative style. 
DEVELOPMENT OF THE INSTRUMENT

The researchers developed an original instrument for use in the project. Several steps facilitated the process. Initially, the research group held several brainstorming sessions. The purpose of these discussions was to determine what types of information needed to be obtained. An exhaustive list of potential questions resulted.

From that list, it was possible to extrapolate major content areas. The researchers decided to construct the instrument around four broad categories: general areas of clinical practice, the treatment process, research and evaluation and professional growth.

At this point, the researchers sought faculty consultation. Dr. Lowell Kuehn, and Lynn Thompson, MSW, provided valuable information to the research team. Furthermore, Ideas and Data: The Process and Practice of Social Research by Sheldon R. Olson and Survey Research Methods by Earl R. Babbie were used as references. An interview format was selected to duplicate the environment in which clinicians normally conduct their practice. It was believed that the comfort of an interview format would elicit a broad range of descriptive data. The rationale for selecting open-ended questions in the interview format was to allow clinicians to express their values. Another function of open-ended questions was to permit the interviewer the freedom to pursue specific information related to the research question. 
The primary task for the three researchers who constructed the interview format was to focus the questions on specific research data while permitting the respondent freedom of expression. To accomplish this task, the researchers relied upon feedback from the pilot sample to make the necessary modifications in the instrument.

\section{PILOT TEST}

The pilot was chosen from among the Portland State University faculty. Each member of the research team chose one member who was currently or had recently been involved in private practice. An effort was made to choose faculty with whom the researchers had some familiarity in order to maximize feedback both in the process of conducting the interview as well as in the informal critique of the interview after its completion. The pilot sample consisted of two Ph.D. psychologists, two Ph.D. social workers, one DSW social worker, and one MSW social worker.

For practice, all members of the research team administered the interview to each other. The interviewee shared subjective feelings and critiqued the interviewer's style after completion of the interview. Major concerns of the research team were length of time needed to conduct the interview, the clarity, specificity and directness of questions, and the linkage of question content to the research question.

In the pilot experiences, the length of time to conduct the interview ranged from 30 to 60 minutes; the goal was 45 minutes. The universal feedback from the pilot sample was for more specific 
questions. Areas indicated as unclear were record keeping, professional growth, and evaluation research. One pilot sample member suggested several questions which more closely linked the interview with the research question. As a result of the pilot feedback and input from all research team members, several modifications were made :

1. The research question was included in the introduction to the interview.

2. Several questions concerning intake, assessment, intervention, and termination process were rewritten to elicit data related more specifically to the research question.

3. The sections concerning evaluation and research and professional growth were completely revised to link more clearly with the research question.

4. A new area was introduced as a result of feedback from a pilot participant: one general question regarding impediments to evaluating clinical practice.

The initial concern of the research team regarding how threatening the subject of evaluation might be to clinicians was not substantiated by the pilot. Consequently, the general modifications of the interview questions toward as much directness, clarity, and specificity as possible increased the likelihood of gathering descriptive data related to the research question.

\section{CHOOSING THE SAMPLE}

The sample was comprised of 20 clinicians in private practice from the greater Portland area. Ten clinicians held masters in social work, and ten were licensed clinical psychologists. It was 
a requirement that each of these 20 clinicians be involved in private practice twenty or more percent of their total working time. The sample was limited to persons primarily involved in private practice to eliminate the impact of agencies upon their evaluation process. It was believed that the constraints that agencies might place on a clinician justified the selection of professionals operating independently.

The manner of selection was random sampling within a specifically chosen population of clinical social workers and licensed clinical psychologists. The researchers utilized the current Registry of Clinical Social Workers and the 1979-80 Directory of the oregon Psychological Association to select the clinicians. The random sampling was accomplished by entering each source at a random point based upon a random number table and selecting every third name thereafter. In the event that an individual was not available, it was agreed that the next name on the list would be substituted so as not to radically skew the random sample.

Initial contact was made by phone. The purpose of the project was explained. Each clinician was asked if he or she would be willing to allocate 45 minutes of their time for an interview with one of the six persons on the research team. The time frame was explained to them, and they were asked to select a convenient date during the 30 day period permitted for data collection.

Twenty clinicians agreed to be interviewed. The final sample included seven male Ph.D. psychologists, three female Ph.D. psychologists, three male MSW's, and seven female MSW's. 
Each clinician who agreed to be interviewed received a letter confirming the date, time and the name of the student who would be the interviewer.

In the process of soliciting 20 clinicians, the researchers contacted a total of 37 practitioners. Fifteen MSW's were contacted. of the fifteen, five were not willing to participate. Of these five had gone into full time clergy work, and four were unable to find the time to allow for the interview. Twenty-two psychologists were contacted before receiving ten confirmations of acceptance. Six of these declined because they did not have the time or did not feel they could contribute anything to the research. Four said they would be willing only in the event that the researchers were not able to get sameone else. (Their names were kept; one of them was later used due to a cancellation of one of the psychologists who had originally accepted.) of the remaining two psychologists who were not able to participate, one had retired and one had died. It suffices to say that most of the clinicians were cooperative and open about their willingness to participate in the research project.

\section{DATA COLLECTION}

Each interview was conducted in the office of the clinician. The length of time to conduct the interviews ranged from 40 to 70 minutes. One interviewer chose to tape the interviews; other team members took extensive notes. It was decided that upon completion of each interview, the interviewer would review and clarify notes taken during the interview. This procedure increased the reliability of the data. 
Group members agreed to recognize the particular style of the individual clinician. Limited discretion in administration of the instrument was allowed in order to facilitate the process of the interview.

\section{PROBLEMS WITH THE INSTRUMENT}

Two limitations of the instrument were noted. The first limitation was found in the structure of the instrument. Portions of the instrument were found to be redundant. Two questions elicited the same response. These questions were found in the assessment section:

Question 1A--"What specific measures do you use in making the decision to refer a client?"

Question 1B--"What specific measures do you use in making a decision not to treat a client?"

It was assumed that a decision not to treat a client often included a referral. The second limitation was realized in the presentation. Despite the discussion of the instrument and practice presentations of the instrument by all members of the research team, two different interviewing styles emerged. It was difficult for the designers to share the specific intent of each question with the three researchers who were not involved in the development of the instrument. The three researchers who developed the instrument used it as a guide to elicit information in specific areas. The other three researchers used the interview in a more structured way. This produced two different groups of data. The data elicited by those who developed the instrument contained more information for each specific question 
than did the data that was collected by those who did not have a part in the instrument design.

This last limitation should be noted as a caution for future researchers. Alternatives that could help eliminate this problem might include total participation by all members of the group in the design of the instrument. This would insure uniform awareness of specific target areas in the instrument. Another alternative is to have just those who develop the instrument do the interviewing to insure consistency in the data gathered.

\section{DATA ANALYSIS}

The process of data analysis involved several steps. First, each member of the research team organized the data from the interviews he/she conducted. Second, a data sheet was made for each interview question. Each member then entered the data from their interviews on these sheets. Third, the data sheets were divided among the team members; the members wrote a narrative summarizing the data on each sheet. Fourth, one team member wrote a narrative description of information from the total sample using the data sheets as a guide.

This process led to linking the assumptions and the research questions with the data. Finally, interpretation and implications of the findings allowed the researchers to arrive at conclusions. 
CHAPTER IV

ANALYSIS

DESCRIPTION OF THE DATA

The description of the data that follows is intended to give the reader a clear understanding of the information that was gathered. The open-ended questions used in the interview elicited a broad range of information. To facilitate the understanding of the data, several charts are provided in addition to the narrative description. The description that follows will duplicate the sequence in which the questions were presented in the interview. The topic areas were: general areas of clinical practice, the treatment process, research and evaluation, and professional growth. It should be noted that the categories that emerged in these topic areas were not mutually exclusive. The responses of several clinicians fell in more than one category.

General Areas of Clinical Practice

The number of years in private practice represented by the sample fell into three groups: seven clinicians had three years or less of private practice experience, six clinicians had four to seven years, and seven clinicians had over seven years.

The research instrument inquired about prior work experience. Five clinicians reported previous experience in hospitals, seven 
clinicians had worked in community mental health centers, and six clinicians reported experience in agencies providing family services, counseling and/or child guidance. Furthermore, three clinicians had worked at colleges, two clinicians had experience in residential treatment, and three clinicians had previously worked in corrections.

Previous Experience with Evaluation

The practitioners were asked if they had been required to do evaluation as part of their earlier work experience, and, if so, to indicate what effect it had on their present practice. Four practitioners had not been required to do evaluation, while 16 had been required to do so. Among those required to do evaluation, two groups emerged: one group of ten clinicians used several of the evaluative procedures previously learned in their current practice, while the other group of six clinicians used few or none of these previously learned procedures.

Eight clinicians mentioned record keeping as a specific procedure learned in previous work settings. Two of these clinicians were utilizing the system they had previously learned, while six had either done away with records or only kept them in a minimal fashion. Two of these practitioners mentioned that their experiences with record systems in prior employment had led to distrust of records, because of confidentiality issues or the ways records were used "politically" in these prior settings.

Two practitioners indicated doing follow-ups as emphasized in their prior employment; two practitioners used tests and assessment 
procedures as they had previously been required to do; one therapist mentioned using case conferences as a carry over from earlier employment.

\section{Activities Outside Private Practice}

Information about outside activities and whether such activities involved evaluation processes was requested. It was found that II clinicians were doing training, i.e., either training staff, doing workshops in the community, or teaching in colleges. Consultation and supervision were other important areas for these professionals. Eleven practitioners were giving consultative support and advice to agencies or supervising other professionals. Nine practitioners were receiving consultation or were participants in peer review groups; such learning experiences were carried out in a formal as well as informal fashion. These groups were not exclusive; some professionals were both giving and receiving consultation. A small number of practitioners mentioned such outside activities as providing diagnostic assessment, doing research, and receiving training.

\section{Current Caseload}

Information about each practitioner's current caseload was obtained. Twelve clinicians indicated that their present caseload consisted of 20 clients or less. Six clinicians reported a caseload of 21 to 30 clients. Two clinicians had caseloads of 31 or more clients. The family unit when seen together was counted as one client. Ten practitioners indicated seeing more women than men while two practitioners saw more men; the others did not specify 
which sex was more predominant. Clients in the middle and upper class seemed more typical; 13 practitioners indicated that the majority of their clients were from such economic backgrounds. Most therapists were serving a population between 20 to 50 years of age. Reasons for treatment most often given were (a) marriage and family issued, (b) adult personal growth and emotional problems, e.g., anxiety and depression, and (c) assessment required for an outside agency. Other problems mentioned included child adjustment, sexual problems, and problems in industrial employment.

\section{Theoretical Orientation}

The clinicians were asked about their theoretical orientation. Six clinicians described themselves primarily as psychodynamic. Psychodynamic is used in the broad sense to include the influences of psychoanalysis, neo-Freudian ideas, and ego psychology. Eight clinicians described themselves as eclectic. Based on what the clinicians said, the researchers defined eclectic as an approach that draws from several treatment modalities. The six remaining clinicians gave a variety of responses regarding their primary theoretical focus. Their respective orientations included the ideas of Jung, behaviorism, relationship theory, humanistic existentialism (Rogers and Gestalt), and transactional analysis. The clinicians listed numerous other influences in their work including Satir's work, rational-emotive therapy and cognitive approaches, hypnosis, biofeedback, bioenergetics, social casework, relaxation training, and reality therapy. 
Treatment Process

Intake. The clinicians were asked about what information they sought in an intake interview. Seven clinicians devoted a large part of the intake interview(s) to defining the client problem(s) and setting up goals based on the client's needs. Eight practitioners indicated intake was a time for a simple screening and obtaining brief demographical data. Another group of seven clinicians used intake to make initial clinical observations. In addition to the activities mentioned above, six practitioners did testing, while six elicited psychosocial history information. One therapist described doing a complete assessment workup which covered five to six sessions.

Record Keeping. The current literature concerning clinical record keeping refers to several formal systems, e.g., Goal Attainment Scaling (GAS) and Problem oriented Record Keeping (PORK). of the 20 clinicians in the sample, only one reported using a formal record keeping system, SOAP. Due to concern for confidentiality, two clinicians kept no record of clinical sessions. Brief recording of summarized process information and demographic data written on either a single sheet of paper or a five by seven inch card was the system utilized by nine clinicians. An extensive record keeping file consisting of demographic data, process recordings for each session, and psychological test results was described by seven clinicians. Three clinicians kept brief recordings only at the client's request; one clinician recorded only dream material; one clinician used a self-designed intake form 
which included demographic data, the referral source, and therapist initial feelings after the first client contact. Table I illustrates the various record keeping systems used by discipline.

\section{TABLE I}

RECORD KEEPING

\begin{tabular}{|c|c|c|c|}
\hline Type of Record & Information Recorded & Psychologist & Worke \\
\hline No Records & $\begin{array}{l}\text { Due to concern for confiden- } \\
\text { tiality }\end{array}$ & 1 & 1 \\
\hline $\begin{array}{l}\text { Forma1 } \\
\text { Record Keeping }\end{array}$ & SOAP & 1 & - \\
\hline $\begin{array}{l}\text { Brief } \\
\text { Recording }\end{array}$ & $\begin{array}{l}\text {-Summarized process information } \\
\text { and demographic data } \\
\text {-Only at client's request }\end{array}$ & 3 & 6 \\
\hline $\begin{array}{l}\text { Extensive } \\
\text { Recording }\end{array}$ & $\begin{array}{l}\text { Process information for each } \\
\text { session, psychological test } \\
\text { results and demographic data }\end{array}$ & 4 & 3 \\
\hline Other & $\begin{array}{l}\text {-Only dream material } \\
\text {-Self-designed intake form } \\
\text { consisting of demographic } \\
\text { data, referral source, and } \\
\text { therapist's initial feelings }\end{array}$ & $\begin{array}{l}1 \\
-\end{array}$ & - \\
\hline
\end{tabular}

Note: These categories are not mutually exclusive.

Assessment. Assessment regarding the decision to treat or refer was made in several ways. Sixteen clinicians made the decision to treat or refer without direct client input. Three clinicians reported that their decision to treat or refer was one of mutual agreement between them and the client. One clinician left the decision entirely to the client.

The predominant reason among the clinicians for referring clients was to obtain the appropriate treatment the clients required. Clients 
whose problems were primarily alcohol or drug abuse were not treated by the majority of this sampling of clinicians; these clients were referred to appropriate treatment facilities instead. Nineteen clinicians refused to treat psychotic patients. The need for an inpatient setting and potential medication necessitated referral. Four clinicians reported that their decision not to treat was based upon their initial discomfort with the client.

Approaches to Treatment. Of the twenty clinicians, four relied primarily on their own general therapeutic framework in which the treatment process was allowed to develop. Eight clinicians reported that they established specific goals and objectives for each client. Rationale for this approach was attributed to the unique nature of each client's specific needs. The remaining eight clinicians utilized a combined approach, having a general therapeutic goal in mind and developing specific objectives for each client.

The process used to develop goals and objectives occurred in three ways. Five clinicians reported that their technique in identifying goals and objectives involved mutual agreement with the client. Six clinicians reported that they developed goals and objectives independent of the client. Five clinicians had the client set his/her own goals and objectives. Four clinicians did not utilize specific goals and objectives in the treatment process. Intervention--Modification of Treatment Plan. Clinicians relied on three primary sources for information indicating modification of the treatment plan. Client self-report was one primary source of information reported by eight clinicians. Clinician's observation of 
changes in the client's behavior or thought structure and frequent repetition of issues was another primary source of information reported by 13 clinicians. Clinician's sensitivity to their gut level feelings, intuition, or frustration level was a third primary source of information reported by four clinicians. Table II illustrates the three sources of information broken down by discipline.

TABLE II

SOURCE OF INFORMATION INDICATING MODIFICATION OF TREATMENT PLAN

Sources of Information

Client Self-Report

Clinicians' Observation

Clinicians' Sensitivity to Their Gut Level Feelings, Intuition or Frustration Level
Psychologist

4

5

2
Social Worker

4

8

2

Note: These categories are not mutually exclusive.

\section{Intervention--Determining How the Intervention is Working.}

Clinicians relied on a combination of several approaches. Client selfreport was chosen by the total sample as a reliable indicator of how well an intervention is working. Clinician's observation of changes in the client's behavior, thought structure, and emotional expression was reported by 13 clinicians as a valid indicator of how well an intervention was working. The clinician's sensitivity to their internal feelings and intuition were indicators of how well an intervention was working. Three clinicians reported use of their sensitivity in this manner. Two clinicians relied on psychological test results 
for information indicating how well an intervention was working. One clinician in the sample received "opinions from significant others" in the client's life, i.e., relative or friend, to help determine how well an intervention was working. Table III illustrates methods used to determine how intervention was working by discipline.

\section{TABLE III}

DETERMINING HOW AN INTERVENTION IS WORKING

\section{Primary Measure Used}

Client Self-Report

Clinicians' Observation

Clinicians' Sensitivity to Their Internal Feelings

and Intuition

Psychological Test Results

Significant Others'

Opinion
Psychologist

10

8

2

1

1
Social Worker

10

5

1

1

0

Note: These categories are not mutually exclusive.

Termination. The decision to terminate treatment involved two factors: (1) who made the decision and (2) what were the influencing variables.

The data suggested three categories regarding who made the decision to terminate treatment: mutual agreement between client and therapist, decision by the therapist without direct client input, and decision by the client alone. The responses to who made the decision was divided equally among the three categories. 
The influencing variables that impacted the decision to terminate treatment were: an initial agreement regarding the number of sessions, economic issues, psychological test scores, goal achievement, and lack of positive impact upon the problem. This list is not representative of all influencing variables, but cites those most often mentioned.

Intuitive Judgment. The use of intuitive judgment effecting decisions in the treatment process fell into two major categories. Nine clinicians reported that intuitive judgment played a large role in treatment decisions and that they relied upon it heavily. Comments of clinicians whose responses fell in this category included "it is . . my way of subjectively evaluating the entire process . . ." and ". . therapists need to be in touch with themselves... in order to know whether or not they are being helpful."

The second major category included five clinicians who said that they used intuitive judgment coupled with behavioral measires. Two clinicians who responded in this manner emphasized the balance that could be achieved by the use of subjective and objective information. The responses of the remaining six clinicians fell into two additional categories. Two practitioners reported that intuitive judgment was the primary basis for treatment decisions. One of these clinicians called intuitive judgment ". . a process at which I often marvel and value." The final four respondents, while acknowledging the value of intuitive judgment, recognized its shortcomings. They noted the importance of using intuitive judgment with 
caution because it was not "foolproof." Table IV illustrates how intuitive judgment was used in treatment decisions by discipline.

TABLE IV

USE OF INTUITIVE JUDGMENT

How Used in Making

Treatment Decision

Played Large Role in

Treatment Decisions

Coupled with

Behavioral Measures

Primary Basis for

Treatment Decisions

Used with Caution

\section{Psychologist}

4

4

2
1

2

Social Worker

5

2

Research and Evaluation

Eleven clinicians had been previously involved in research projects concerning evaluation issues. Eight of the 11 clinicians saw no relationship between past research projects and their present practice. Two of the 11 clinicians related evaluative information from past research projects to their practice. Techniques of sentence completion tests, follow-up studies, and limiting the number of therapy sessions were the major techniques these clinicians utilized in their private practice.

When asked whether they read research articles, 13 clinicians said they did. The benefits of reading research articles were related to client treatment and the acquisition of new perspectives and ideas. One clinician read research articles for consultation purposes only. 
The problems encountered in the evaluation of private practice were varied. Six areas of concern were identified with some clinicians identifying more than one area. The areas of concern were: (1) problems with evaluative tools, (2) time, (3) subjectivity of therapy--transference and countertransference issues, (4) quality of treatment, (5) confidentiality, and (6) client resistance. One clinician responded that evaluation was not used and therefore no problems were experienced. Table $V$ illustrates the problems encountered in evaluating private practice by discipline.

\section{TABLE V}

PROBLEMS ENCOUNTERED IN EVALUATING

Areas of Concern

Problems with

Evaluative Tools

Time

Subjectivity of Therapy

Quality of Treatment

Confidentiality

Client Resistance
Psychologist

4

3

1

1

1

3
Social Worker

4

2

2

2

1

I

Note: These categories are not mutually exclusive.

Professional Growth

Consultation. The clinicians were asked two general questions about their professional growth. The first question had four parts: 
1. Are you involved in consultation with other professionals or agencies? If yes:

A. In giving?

B. In receiving?

C. Can you verbalize how this might influence your evaluation processes?

For the sake of clarity, parts A, B, and C of the question will be discussed separately.

Giving Consultation. Three clinicians reported that they were not involved in giving consultation. Of those clinicians who were involved in giving consultation, six served as consultants to agencies; two provided consultation to medical facilities; two were court consultants; and one provided training at a church. Supervision of other professionals was provided by seven clinicians, and two practitioners served as consultants to business or industry. Table VI illustrates the breakdown by discipline of those clinicians giving consultation.

\section{TABLE VI}

GIVING CONSULTATION

Organizations and Individuals Receiving Consultation

Psychologist Social Worker

Social Service Agencies

3

3

Medical Facilities

2

Judicial System

1

1

Religious Organizations

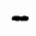

1

Business/Industrial organi2

zations

Clinical Professionals

Note: These categories are not mutually exclusive 
Receiving Consultation. The broad category that emerged in this area was the reception of consultation from colleagues and/or other professionals. The respondents referred to both "formal" and "informal" consultation. The researchers thought that it was necessary to define these two types of consultation.

Formal consultation referred to ongoing supervision from another professional (e.g., an MSW receiving supervision from a $\mathrm{Ph} . \mathrm{D}$.$) or to$ the utilization of the expertise of other professionals in special problem areas (e.g., consulting an M.D. for medication). Informal consultation referred to the case sharing that occurred during professional peer interactions. A distinction between the two types of consultation was that formal consultation implied a one way exchange of information whereas informal consultation implied a mutual process. Of the 17 clinicians who received consultation from colleagues and/or other professionals, 6 received formal consultation, 13 received informal consultation, and 2 received both. other responses to this question included those from two clinicians who received no consultation, two clinicians who received personal therapy, and one clinician who consulted with a business manager regarding non-clinical issues. Table VII illustrates the type of consultation received by the clinicians by discipline.

Influence of Consultation. The final part of the question asked about the influence of consultation on the clinicians' evaluation processes. Four clinicians said that there was no noticeable effect. Eight clinicians said that consultation provided them with objective feedback. Eight clinicians pointed out that the 
TABLE VII

RECEIVING CONSULTATION

Type of

Consultation Received

Psychologist

Social Worker

Personal Therapy

1

1

Formal Consultation

3

3

With Colleagues

Informal consultation

5

8

With Colleagues

Consultation with

1

Business Manager

consultation provided new information and insights as well as an opportunity to improve skills. Finally, three clinicians stated that consultation provided mutual support for them. Table VIII illustrates the influence of consultation on the clinicians' evaluative processes by discipline.

TABLE VIII

INFLUENCES OF CONSULTATION ON EVALUATION PROCESSES

Influence

No Noticeable Effect

Provides Objective

Feedback

Provides New Information

and Insights and oppor-

tunity to Improve Skills

Provides Mutual Support
Psychologist

3

3

4

1
4

Social Worker

1

5

2 
Attendance at Workshops, Seminars, Conferences. The second question on professional growth included two sections: "How often do you attend workshops, seminars, and conferences?" and "How does the information you gather there impact on your private practice?" Regarding the frequency of attendance, nine clinicians reported that they attended workshops or participated in training activities once a month or more. Responses from ten clinicians indicated participation in these activities three to six times a year. Finally, three clinicians did not give numerical estimates of their attendance. of these, two said that they attended "frequently," and one said "seldom." Table IX illustrates the frequency of attendance at workshops, seminars and conferences by discipline.

TABLE IX

ATTENDANCE AT WORKSHOPS, SEMINARS, CONFERENCES

$\begin{array}{lcc}\text { Frequency of Attendance } & \text { Psychologist } & \text { Social Worker } \\ \text { Monthly or More } & 6 & 3 \\ \text { Three to Six Times a Year } & 3 & 7 \\ \text { Two Times a Year } & 1 & - \\ \text { "Frequently" } & 1 & 1 \\ \text { "Seldom" } & 1 & -\end{array}$

Regarding the impact of workshops, seminars and conferences on their practice, 18 clinicians, 10 social workers and 8 psychologists indicated that they expanded their knowledge and learned new skills to integrate into their practice as applicable. In addition, one of 
these clinicians stated that these activities promoted the field, and another stated that they helped confirm professional identity and ethics. The remaining two clinicians, both psychologists, reported that training activities were of limited use in treatment. One of these practitioners attended few workshops; the other felt that it was difficult to find a good conference or training session from which to learn new information.

\section{Additional Data}

In the process of interviewing the 20 clinicians, additional data was gathered. This information related to the use of testing and single subject design by the clinicians.

Several practitioners gave information about their testing procedures when asked about intake, assessment and termination. The MMPI was the instrument used by seven practitioners. The Rorschach, the Wechsler Adult Intelligence Scale and various forms of sentence completion tests were used by three clinicians. Other testing instruments were cited only once. These tests were the California Psychological Inventory, Stanford-Binet, Taylor Johnson Temperament Analysis, Leakey's Interpersonal Adjective Checklist, Hudson Scales, Locke-Wallace Marital Adjustment, Sexual Interaction Inventory, Measurement of Depression (by William Fung) and the Thematic Apperception Test. Though not a pencil and paper instrument, one clinician's use of biofeedback should be mentioned.

Eight psychologists and three social workers were doing testing. The primary use of testing was for assessment early in treatment. 
Three practitioners noted use of some tests on a pre and post basis. One clinician used testing repeatedly during treatment with some clients.

Single subject design was not used by this sampling of clinicians. However, two clinicians mentioned the tracking of behaviors. One of these clinicians occasionally had clients count their problem behaviors, while the other clinician kept some data from biofeedback sessions.

Conclusion

The intent of this section was to provide a description of the data. An understanding of the data will facilitate the presentation of the interpretations and implications.

\section{INTERPRETATIONS AND IMPLICATIONS}

The researchers' goal in this section is an objective analysis of the data. However, it should be pointed out that three values or beliefs of the researchers have influenced the data analysis. These tenets were:

A. It was assumed that clinicians want to improve the effectiveness of their practice.

B. It was assumed that evaluation was a tool that can be used to improve the effectiveness of clinical practice.

C. It was assumed that clinicians may be engaged in evaluation of their practice whether or not they recognized the process as evaluative.

The following discussion of the interpretations and implications of the data will use the assumptions listed in the methodology as its framework. 
It was assumed that the researchers would be able to describe the extent to which clinicians do evaluate.

In response to this assumption, a description of activities which provided evaluative information to clinicians will be presented. It was not the intent of the researchers to obtain quantitative information concerning these activities. The data indicated that there were more evaluative activities occurring than may have been recognized by the clinicians. The primary activities which provided evaluative information were:

1) Consultation--All members of the sample were involved in giving or receiving consultation. Clinicians utilized consultation as a self-evaluative tool.

2) Client self-report--All 20 respondents utilized client self-report as an indicator of the effectiveness of treatment. Clinicians relied upon verbal feedback and behavioral observations for client self-report, as opposed to the more formalized methods described in the literature review.

3) Mental processes--The researchers operationally defined this term as internal intellectual activities undertaken to bring about a desired result. Intuitive judgment was a particular mental process utilized by the clinicians in this sample. The researchers defined intuitive judgment as a subjective evaluation of the therapistclient interaction. All 20 clinicians recognized and utilized intuitive judgment in their practice as an evaluative tool. Some clinicians valued their intuitive reactions highly and therefore relied upon this tool extensively, while other clinicians were more skeptical of their intuitive thought and used it with more caution. 
4) Record keeping--Seventeen clinicians utilized informal record-keeping systems. The literature review recognized formal record-keeping systems as an evaluative tool. Due to the informal record-keeping systems utilized by the respondents, their evaluative nature was uncertain.

Given the widespread use of the above activities, it was evident that evaluation was occurring. The researchers identified specific evaluation activities which occupied space within the clinician's work frame. However, the data gathered did not indicate how much of a priority clinicians placed upon evaluation.

It was assumed that evaluative information could be obtained by analyzing techniques currently used by the clinicians.

The most widely used techniques were chosen for the analysis. 1) Psychological testing--In the literature review, psychological testing was recognized as an evaluative tool. Half of the sample utilized psychological testing. Testing was primarily used early in treatment for assessment. Three clinicians used preand post-tests for evaluative purposes.

2) Record keeping--The researchers were unable to obtain conclusive evaluative information from the current techniques used for record keeping. However, informal techniques of record keeping, either brief notes or an extensive file, have the potential to provide evaluative information. More useful evaluative information would be gained by implementation of a standardized format within each clinician's practice. 
3) Client self-report--Clinicians relied on the client's perception of progress in treatment. Client self-report was used in the setting of goals, modification of treatment, and in decisions regarding termination. Client self-report was seen by clinicians as a valuable indicator of the effectiveness of treatment.

4) Consultation--Peer consultation played a major role in clinicians' self-evaluation. Case review, information sharing regarding treatment techniques, and objective feedback were ways in which evaluative information was provided. Clinical supervision was also used by clinicians in self-evaluation. Consultation gave credence to the network of private practitioners by providing evaluative feedback concerning their practice.

The preceding analysis of clinical techniques substantiated the assumption that these techniques do provide evaluative information.

It was assumed that clinicians have a working familiarity with evaluative procedures which would have an impact upon their current practice. Such knowledge could come from four areas: graduate School training, professional experience prior to and/or during private practice, research experience, and contact with other professionals in the social service network (e.g., consultation, workshops, conferences).

Each of these areas will be discussed separately.

1) Graduate school training--Sporadic information made it difficult to substantiate that familiarity with evaluative procedures came from graduate school training. However, training in the use of psychological tests, involvement in research theses, and exposure to a multiplicity of theories did imply that some training in the use of evaluative tools occurred. 
2) Experience prior to private practice--Eleven clinicians indicated that they became familiar with evaluative procedures during previous clinical experiences. Some specific evaluative procedures mentioned were record keeping, follow-up studies, testing, and assessment procedures. The data indicated that individual choice dictated whether or not such techniques were currently used.

3) Research experience--Eleven clinicians had previously been involved in research projects concerning evaluation issues. However, only two clinicians related this experience to their current practice.

4) Contact with other professionals--All 20 clinicians were engaged in both consultation and training. These activities provided the clinicians with information about evaluative procedures. Fifteen clinicians reported that contact with other professionals in the social service network had an impact upon their practice.

Given the number of clinicians involved in consultative activities and the space which these activities occupied within the clinicians' work frame, it is clear that consultation and training had the greatest influence. Graduate school training, prior professional experience and research experience did not seem to influence current practice as significantly.

It was assumed that the theoretical orientation and discipline of the clinician would influence the utilization and nature of evaluation procedures. There were two issues involved here. First, the researchers believed that those clinicians with a behavioral orientation would be more likely to use single subject designs, or variations the reof, than those clinicians with a psychoanalytic orientation. Second, the researchers believed that due to extensive training in the use of tests, psychologists would use more formal testing procedures than social workers. 
In this sample of clinicians, the data did not substantiate the belief that the theoretical orientation had an impact on the use of single subject design. The data did indicate that the discipline of the clinician influenced the use of a specific evaluation procedure, testing.

Six clinicians reported that they were influenced by behavioral theory. Two of these six clinicians utilized an informal variation of single subject design, i.e., counting behaviors. No clinicians reporting a psychoanalytic orientation utilized single subject designs, or variations thereof. The data was inconclusive due to a lack of clinicians in this sample with a strictly behavioral orientation. Psychologists did use more formal testing procedures than social workers. Of the sample, eight out of ten psychologists used psychological testing, while three out of ten social workers used testing. Thus, the data supported the assumption that discipline influenced the use of testing.

It was assumed that time and money would put some constraints upon the use of evaluation in private practice. The crucial variable here would be the value the clinician placed on evaluation.

Five clinicians in the sample reported that time was a variable which influenced their use of evaluation. There was no mention of money as a constraint. Therefore, the findings indicated that time was a factor, although not universally addressed by the sample. The relationship between time and money and the value clinicians placed on evaluation cannot be substantiated. 
It was assumed that the more involved clinicians were in activities outside their private practice (e.g., consultation, workshops, training), the more likely that these individuals would engage in evaluation of their practice. The assumption was based on the belief that frequent contact with other professionals would expand the clinicians' awareness of evaluation and therefore increase the likelihood that they would incorporate evaluation techniques into their practice.

The universal use of consultation by this sample indicated that it was recognized as a valuable technique. Clinicians used consultation for a number of purposes, most of them evaluative: objective feedback, new information and insight, opportunity to improve skills, and mutual support. Due to the widespread use of consultation and its evaluative nature, it was clear that consultation provided the opportunity for clinicians to engage in the evaluation of their practice. Furthermore, the process of consultation served to maintain a network among clinicians that enhanced the professional growth of each member and subsequently impacted upon their practice.

It was assumed that the record keeping process utilized by clinicians would be one indicator of their evaluative styles.

The data did not substantiate that the record keeping process was indicative of the clinicians' evaluative styles. It was found that record keeping fell into two categories: formal record keeping, which was described in the literature review as an orderly standardized system which provdied a data base, and informal record keeping, which included a variety of non-standardized personalized styles. Seventeen clinicians utilized informal record-keeping processes, and one clinician utilized a formal system--SOAP. The implication of this data is that, although standardized record keeping systems exist, clinicians prefer to develop and use their own personalized systems. 
This concludes the description, interpretations and implications of the data. General findings and conclusions in response to the research question will be presented in the final chapter. 
CHAPTER V

\section{CONCLUSION}

The researchers began by defining the research question. From there, the focus broadened to include the literature review, the development of the methodology, and the collection and analysis of data. The following section will concentrate on the research question and draw the major conclusions. The research question was:

To what extent and in what way are licensed clinical psychologists and clinical MSW's in the private sector involved in evaluating their practice?

a. Are these clinicians using formative and/or summative evaluation?

b. What techniques and/or mental processes do they use?

It seems most logical to start the discussion with the subsections of the question as they are more limited in scope.

FORMATIVE AND SUMMATIVE EVALUATION

It was found that formative evaluation was more prevalent than summative. Clinicians were involved in various activities which were used to assess the treatment process at regular intervals as in formative evaluation. These activities included intuitive judgment, mental processes, client self-report, record keeping, consultation, 
and limited use of psychological testing for assessment. Summative evaluation, by definition, is used to determine the overall effectiveness of the entire treatment process. Sumative evaluation was used in a minor way with post-testing and follow-up studies. The data suggests that formative evaluation was more applicable to the process of clinical treatment than summative.

TECHNIQUES AND MENTAL PROCESSES USED

Those techniques available to practitioners fell into two categories: formal, empirical and informal, non-empirical. The procedures most commonly used by this sampling of clinicians were client self-report, intuitive judgment, consultation and informal record keeping. From this list of activities, it is evident that the informal, non-empirical procedures were more prevalent.

The literature review demonstrated the availability to clinicians of a wide variety of formal, empirically based, standardized systems. Formal systems have been developed in the areas of record keeping, single subject design, testing and client self-report. With the exception of testing, the current data indicated that only one clinician was using a formal standardized system (SOAP). It was evident from the sample that clinicians in private practice are not making use of formal evaluative systems, but are developing their own informal systems.

The theoretical orientation of the clinicians did not impact on their tendency to use informal evaluative procedures. However, 
the discipline of clinicians did have an impact on the use of a specific type of formal evaluation, i.e., testing.

Another area that impacted significantly upon the clinicians' evaluative style was involvement in consultation and training activities. These activities did not lead to the use of formal evaluative procedures but did serve as a means for evaluation of practice.

Based on the data gathered from the sample, the researchers have concluded that these clinicians perceived evaluation to be synonymous with the formal evaluation described in the literature review. Therefore, the problems they associated with evaluation are peculiar to formal evaluation. The ongoing informal evaluation utilized by this sampling of clinicians was not subject to the same problems as the formal systems. This could account for the fact that clinicians were creating systems applicable to their individual practice.

Given that therapy could be regarded as an art unique to the individual clinician, and that the evaluation procedures used by this sample were a result of the clinicians' own creativity, evaluation could also be interpreted as an art.

TO WHAT EXTENT AND IN WHAT WAY

The sub-sections of the research question were addressed in the preceding paragraphs. The focus will now be upon the core of the research question. The ways in which clinicians evaluate their practice were described in the discussion of (a) formative and summative evaluation and (b) the techniques and mental processes used. 
Regarding the extent to which clinicians evaluate, two important points emerged. First, given the low prevalence of empirical, formal systems, the researchers have concluded that these systems had a low priority in the clinicians' practice. On the other hand, nonempirical, informal evaluation systems were a constant, natural part of the therapeutic process. The prevalence of these activities indicated that clinicians placed a higher priority upon informal systems.

The second major point was the impact of consultative activities upon the clinicians' evaluative procedures. The current literature does not address the issue of consultation as a viable tool for evaluation of clinical practice. However, the data indicated that a natural helping network, based on consultation, was in existence within the professional community. Clinicians were relying upon this network to provide them with a means to evaluate the effectiveness of their practice.

\section{RECOMMENDATIONS FOR FUTURE RESEARCH}

Several areas emerged that could provide a basis for further study. To determine whether the results of the current research could be replicated, the evaluative procedures of a larger sampling of clinicians should be studied. Inquiry of this nature should address the issue of the priority of evaluation. Specifically, attempts should be made to determine the amount of time that clinicians devote to evaluative activities. Such study would expand the data 
base provided by the current research. If this were done, a more comprehensive understanding of the extent to which clinicians evaluate could be achieved.

Regarding formal and informal evaluation procedures, future research could take two directions:

1) A study of the ways in which formal, empirical evaluation systems could become applicable to private practice could be done. This should include a determination of what tools could be developed for use with different treatment modalities and what value these tools would have in private practice.

2) A study of the informal evaluative procedures currently used by clinicians could be conducted. This study should attempt to assess the validity and reliability of these procedures.

Another issue that merits further study is consultation. The data in the current study indicated that the natural helping network among clinicians is an unrecognized resource. Study of this network would provide valuable information about the way it contributes to the evaluative process of clinicians.

\section{A FINAL CONCERN}

The final issue to be addressed is that of accountability. The increasing emphasis on accountability in the mental health profession was discussed in the literature review. Evaluation is the primary mechanism to insure accountability and to maintain an appropriate standard of conduct within the professional community. As indicated in the literature review, the demand for accountability is currently met with formalized measures. A question that needs to 
be answered is whether or not the predominantly informal, nonempirical evaluation processes currently being used provide a sufficient answer to the issue of accountability. 


\section{BIBLIOGRAPHY}

Alwin, D. F. and Tessler, R. C., "Causal Models, Unobserved Variables and Experimental Data," American Journal of Sociology, Vol. 80 (1), July 1974, pp. 58-86.

Attkissen, Clifford C.; Hargreaves, William A.; Horawitz, Mardi J. and Sorensen, James E. (eds.), Evaluation of Human Service Programs, New York: Academic Press, 1978 .

Babbie, Earl R., Survey Research Methods, Belmont, Calif.: Wadsworth Publishing Company, Inc., 1973.

Bankowsky, Marilyn L., "Adapting the POMR to Community Child Health Care," Nursing Outlook, Vol. 20 (8), August 1977, pp. 510-518.

Bednar, Richard and Lawlis, G. Frank, "Empirical Research in Group Psychotherapy," Allen Bergin and Sol Garfield (eds.), Handbook of Psychotherapy and Behavior Change, New York: John Wiley and Sons, Inc., 1971, pp. 812-838.

Bergin, Allen and Garfield, Sol (eds.), Handbook of Psychotherapy and Behavior Change, New York: John Wiley and Sons, Inc., 1971.

Bloom, Martin and Block, Stephen, "Evaluation of Single Intervention," Journal of Social Service Research, Vol. 2 (3), 1979, pp. 301-310.

, "Evaluating One's Own Effectiveness and Efficiency," Social Work, Vol. 22 (2), March 1977, pp. 130-136.

Bloom, Martin, The Paradox of Helping: Introduction to the Philosophy of Scientific Practice, New York: John Wiley and Sons, Inc., 1975.

Bristo, Margaret C., Handbook on Social Case Recording, Chicago: University of Chicago Press, 1936.

Buros, Oscar K., Personality: Test and Review, Highland Park, N.J.: The Gryphan Press, 1970.

Caro, Francis G. (ed.), Readings in Evaluation Research, New York: Russell Sage Foundation, 1977.

Casselman, B., "On the Practitioner's Orientation Toward Research," Smith College Studies in Social Work, Vol. 8 (3), 1972, pp. 211233. 
Chassan, J. B., "Some Difficulties, Pitfalls, and Limitations of the Extensive Model," Chapters 6 and 7 in Chassen J. B., Research Design in Psychology and Psychiatry, Century Psychology Series, 1967.

Chommie, P. H., "Evaluation of Outcome and Process," Social Work, Vol. $19(6), 1974$, pp. 682-687.

Clarkson, Quentin D.; Koroloff, Nancy; Neuberger, Wayne and Hines, Susan, Goal Attainment Scaling: A Review, Portland, Oregon: Portland State University Regional Research Institute for Human Services, 1976.

Cline, David w.; Rouzer, David L. and Bransford, David, "Goal Attainment Scaling as a Method for Evaluating Mental Health Programs," American Journal of Psychiatry, Vol. 130 (1), 1973, pp. 105-108.

Cohen, M. M., "The Role of Research in Federation and Agency Planning: A Critical Analysis," Journal of Jewish Communal Service, Vol. 42 (1), 1965, pp. 82-91.

Compton, B. and Galaway, B., Social Work Processes, Homewood, Ill.: Dorsey Press, 1975.

Coursey, Robert D. (ed.), Program Evaluation for Mental Health: Methods, Strategies, Participants, New York: Grune and Stratton, 1977 .

Cox, Gary B., "Managerial Style: Implications for the Utilization of Program Evaluation Information," Evaluation Quarterly, Vol. 1 (3), 1977, pp. 499-508.

Davis, Howard D. and Salasin, Susan, "The Utilization of Evaluation," Handbook of Evaluation Research, Vol. 1, Beverely Hills, Calif.: Sage Publication, 1975.

Fanshel, D., "Sources of Strain in Practice-Oriented Research," Social Casework, Vol. 47 (6), 1966, pp. 357-362.

Fischer, Joel, Effective Casework Practice: An Eclectic Approach, New York: McGraw-Hill Book Company, 1978.

, "Is Casework Effective" A Review," Social Work, Vol. 18 (1), 1973), pp. 5-20.

Forcese, Dennis and Richer, Steven, Social Research Methods, Englewood Cliffs, N.J.: Prentice-Hall, Inc., 1973. 
Freedman, Alfred M., Journal of the American Academy of Psychoanalysis, Vol. 7 (1), New York: John Wiley and Son, Inc., 1979, pp. 1-5.

Frings, John; Kratovil, Ruth and Polemis, Bernice, An Assessment of Social Case Recording (An Experimental Study in Two Family Agencies), Family Service Association of America, 1958.

Galvin, D. E., "Program Evaluation in Michigan Rehabilitation Service," Social and Rehabilitation Record, Vol. 1 (10), 1974, pp. 28-31.

Garwick, Geoffrey, Commentaries on Goal Attainment Scaling, Minneapolis, Minnesota: Program Evaluation Project, 1975. , Guidelines for Goal Attainment Scaling, Minneapolis, Minnesota: Program Evaluation Project, 1975.

Geismar, Ludwig and LaSorte, Michael, "Research Intervention--A Positive Case," American Journal of Orthopsychiatry, Vol. 38 (3), 1968, pp. 444-456.

Giordano, Peggy, "The Client's Perspective in Agency Evaluation," Social Work, Vol. 22 (1), January 1977, pp. 34-40.

Gottman, John M., and Leiblum, Sandra R., How to do Psychotherapy and How to Evaluate It, New York: Holt, Rinehart \& Winston, Inc., 1974 .

Grey, Alan and Dermody, Helen, "Reports of Casework Failure," Social Work, Vol. 8 (2), 1963, pp. 4-9.

Greenwald, Stephen M., The Relationship of Goal Attainment Scaling to Psycho-Dynamic Constructs, Minneapolis, Minnesota: Hennepin County Mental Health Center

Guttentag, M. and Saar, S. (ed.), Evaluation Studies, Vol. 2, Beverely Hills, Calif.: Sage Publication, 1977.

Hardison, James C. and Shank, Steven B., A Client Centered Evaluation Support System, Salem, Oregon: Mental Health Division, 1977.

Haynes, J., An Evaluation of Psychosocial Casework Using the Single Subject Design: First Findings, paper presented at the Council on Social Work Education 23rd Annual Program Management, Phoenix, Arizona: March 1, 1977.

Ho, Man Keung, "Evaluation: A Meaning of Treatment," Social Work, Vol. 21 (1), January 1976, pp. 24-27.

Hollis, F., "Evaluation: Clinical Results and Research Methodology," Clinical Social Work Journal, Vol. 4 (3), Fall 1976, pp. 204-212. 
Hopps, J. G., "Evaluation and Accountability in Child Welfare," Child Welfare, Vol. 54 (3), 1975, pp. 155-166.

Houts, Peter S. and Scott, Robert A., Behavioral Objectives and Goal Attainment Scaling: Unstrange Bed Fellows, Hershey, Pennsylvania: Milton S. Hershey Medical Center.

Howe, Michael, "Casework Self-Evaluation: A Single Subject Approach," Social Service Review, Vol. 48 (1), 1974, pp. 1-23.

"Using Clients Observations in Research," Social Work,

Vol. 21 (1), January 1976, pp. 28-32.

Hudson, Walter W., "Elementary Techniques for Assessing Single Client/Single Worker Intervention," Social Service Review, vol. 15 (3), 1977, pp. 31l-326.

Jayaratne, Srinika, "Analytic Procedure for Single Subject Desjgn," Social Work Research and Abstracts, Vol. 14 (3), Fall 1978, pp. 30-40.

J. C. H., G.O.R.K., Salem, Oregon: Evaluation Service, Mental Health Division, 1975.

Kadushin, Alfred, The Social Work Interview, New York: Columbia University Press, 1972.

Kahn, Theodore C., Cameron, James T. and Giffen, Martin B., Methods and Evaluation in Clinical and Counseling Psychology, New York: Pergaman Press, Inc., 1975.

Kiesler, Donald, "Experimental Designs in Psychotherapy Research," in Allen Bergin and Sol Garfield, Handbook of Psychotherapy and Behavior Change, pp. 36-74.

Kiresuk, Thomas J. and Sherman, Robert E., "Goal Attainment Scaling: A General Method for Evaluating Comprehensive Community Mental Health Programs," Community Mental Health Journal, Vol. 4 (6), 1968, pp. 443-453.

, "A Reply to the Critique of Goal Attainment Scaling," Social Work Research and Abstracts, Vol. 13 (2), 1977, pp. 10-11.

Kuehn, Lowell, Ph.d., Professor of Sociology at The Evergreen State College, Olympia, Washington. Personal interviews (nine)

between October 25, 1975 and February 16, 1980. 
Leivtenberg, H., "The Use of Single Case Methodology in Psychotherapy Research," Journal of Abnormal Psychology, Vol. 82 (1), August 1973, pp. 87-101.

Lewis, G. F. and Lu, E., "Judgment of Counseling Process: Reliability Agreement and Error," Psychology Bulletin, Vol. 78 (1), 1972, pp. 17-20.

Lewis, H., "The Use and Place of Research in the Administration of the Social Agency," Child Welfare, Vol. 44 (1), 1965, pp. 21-25.

Lippitt, R., "The Use of Social Research to Improve Social Practice," American Journal of orthopsychiatry, Vol. 35 (4), 1976, pp. 633-668.

Loftus, Geoffrey R. and Levy, Rona I., "Statistical Evaluation of Clinical Effectiveness," Social Work, Vol. 22 (6), 1977, p. 504.

Lusby, Sarah T. and Rodney, Bernice D., "One Agency's Solution to the Recording Problem," Social Casework, Vol 54 (10), December 1973, pp. 586-590.

Maas, Heary, "Assessing Family and Child Welfare Practice," Social Work, Vol. 24 (5), September 1979, pp. 365-374.

Martens, Wilma M. and Holmstrup, Elizabeth, "Problem-Oriented Recording," Social Casework, Vol. 55 (9), 1974, pp. 554-561.

Mitchell, K. R., "Repeated Measures and the Evaluation of Change in the Individual Client During Counseling," Journal of Counseling Psychology, Vol. 16 (6), 1979, pp. 522-527.

National Association of Social Workers, "Recording in Social Work," Encyclopedia of Social Work, pp. 1161-1168.

National Institute of Mental Health, Psychotherapy Change Measurement, Rockville, Maryland, DHEW Publication, 1975.

Nicholds, Elizabeth, In-Service Casework Training, New York: Columbia University Press, 1976.

Olson, Sheldon R., Ideas and Data: The Process and Practice of Social Research, Illinois: Dorsey Press, 1976.

Patton, Michael Q., Utilization Focused Evaluation, Beverly Hills, Calif.: Sage Publication, 1978.

Perlman, Helen, Social Casework: A Problem Solving Process, Chicago, Ill.: University of Chicago Press, 1957.

Pillavin, I. and McDonald, T., "On the Eruits of Evaluation Research for the Social Services," Administration in Social Work, Vol. 1 (1), 1977, pp. 63-70. 
Rauneburg, Ronald L.; Belair, Robert R. and Barlow, Steven R., P.O.R.S., Tacoma, Wash.: Research and Evaluation Department of Comprehensive Mental Health Center.

Reagles, K. W. and O'Neill, J., "Single-Subject Designs for Client Group: Implication for program Evaluation," Rehabilitation Counseling Bulletin, Vol. 21 (1), 1977, pp. 136-142.

Rosenblatt, A., "The Practitioner's Use and Evaluation of Research," Social Work, Vol. 13 (1), 1968, pp. 53-59.

Schell, Pamela L. and Campbell, Alla T., "POMR--Not Just Another Way to Chart," Nursing Outlook, Vol. 20 (8), 1977, pp. 510-514.

Schinke, S., "Evaluation Social Work Practice: A Conceptual Model and Example," Social Casework, Vol. 60 (4), 1979, pp. 195-200.

Schmidt, J. A., "Research Techniques for Counseling: The Multiple Baseline," Personnel and Guidance Journal, Vol. 14 (1), 1978, pp. 19-24.

Seaberg, James R. and Gillispie, David F., "Goal Attainment Scaling: A Critique," Social Work, Research and Abstract, Vol. 13 (2), 1977, pp. 4-9.

Seaberg, James R., "Systemized Recording: A Follow-Up," Social Work, Vol. 15 (4), October 1970, pp. 32-41.

Shaughnessy, Mary Kay and Burnett, Carolyn N., "Implementation of the Problem-oriented Progress Note in a Skilled Nursing Facility," Physical Therapy, Vol. 59 (2), 1979, pp. 160-165.

Shostrom, E. L. and Riley C., "Parametric Analysis of Psychotherapy," Journal of Consulting and Clinical Psychology, Vol. 32 (6), 1968, pp. 628-632.

Shyne, Ann, "Evaluation of Results in Social Work," Social Work, Vol. 8 (4), 1963, pp. 26-33.

Solnick, J. V.; Birnbrauer, J. S. and Peterson, C. R., "Design and Interpretation of Studies of Single Subject," American Journal of Mental Deficiency, Vol. 79 (2), 1974, pp. 191-203.

Thomas, Edwin J., "The B.E.S.D.A.S. Model for Effective Practice," Social Work Research and Abstracts, Vol. 13 (2), 1977, pp. 12-16.

Thompson, Lynn, M.S.W., Associate Professor at Portland State University, Portland, Oregon. Two personal interviews (October 26, 1979 and November 15, 1979). 
Timms, Noel, Recording in Social Work, Routledge and Kegan Paul, London, 1972.

Toftus, G. and Levy, R., "Statistical Evaluation of Clincal Effectiveness," Social Work, Vol. 22 (6), 1977, pp. 504-505.

Walins, Martin, "Measuring the Effect of Social Work Intervention," in Polansky, Norman (ed.), Social Work Research, Chicago: University of Chicago Press, 1960, pp. 247-272.

Washow, Irene E. and Parloff, Morris B., Psychotherapy Change Measures, nHEW Publication, 1975, pp. 74-120.

Wattie, Brenda, "Evaluation Short-Term Casework in Family Agency," Social Casework, Vol. 54 (10), 1973, pp. 609-616.

Weed, Lawrence L., Medical Records, Medical Education, and Patient Care, Chicago, Ill.: Yearbook Medical Inc., 1970.

Weiss, Carol, "Alternative Models of Program Evaluation," Social Work, Vol. 19 (6), 1974, pp. 675-681.

Wilson, Robert A., "An Evaluation of Intensive Casework Impact," Public Welfare, Vol. 25 (4), 1967, pp. 301-306.

Worthen, Blaine R. and Sanders, James R., Educational Evaluation Theory and Practice, Worthington, Ohio: Jones Publishing Company, 1973.

Zusman, Jack and Wurster, Cecil (ed.), Program Evaluation: Alcohol, Drug Abuse and Mental Health Services, London: Lexington Books 1975. 
APPENDIX

INTERVIEW FORMAT AND CONFIRMATION LETTER 
I'm one of six graduate students at Portland State University School of Social work. We are conducting a research project focusing on evaluation procedures utilized by private practitioners.

The evaluation of clinicians' practice is a concern being viewed on a national level in the mental health profession. I am interested in your thoughts and feelings as well as any approaches you use in dealing with evaluation issues. Our research question is: "To what extent and in what ways do clinicians evaluate their private practice?" I would like to share about 45 minutes of your time to discuss the issues of evaluation as they relate to your practice.

The interview will explore several areas: First, some general questions concerning your clinical practice; second, questions regarding the treatment process; third, questions concerning research; and finally, questions regarding professional growth.

The confidentiality shared among professionals will be extended to this interview.

We will be sending you a summary of our research in April upon completion of this project.

\section{Questions regarding general areas of your clinical practice:}

1. How long have you been in private practice?

A. What kinds of clinical experiences have you had? If agency experience: Were you required to do any evaluation? What effect did that evaluative experience (in the agency) have on your present practice?

B. Are you presently involved in any clinical activities outside of your private practice (consultation, training)? Do these activities involve evaluation processes? 
2. How many clients are your presently seeing?

A. Would you define your client population?

Age range--

Sex--

Socio-economic status--

Specific problems--

3. What is your theoretical orientation (seek specific information-specialization)?

\section{Intake Questions}

1. What information do you seek in an intake interview (initial session, telephone or in person)?

2. How do you go about recording information? Do you use a specific record-keeping system (SOAP, GAS, GORK, PORK)? 


\section{Assessment}

1. A. What specific measures do you use in making a decision to refer the client?

B. What specific measures do you use in making a decision not to treat a client?

2. A. I am aware that there are many different ways to approach the treatment process. Some clinicians develop specific goals and objectives; others have a general therapeutic goal in mind for all clients. Would you please tell me what your approach is?

B. Tell me about the process used to identify goals and objectives.

\section{Intervention}

1. What indicators do you rely on to modify the treatment plan (intervention methods)? 
2. How do you know when the intervention is working?

\section{Termination}

1. How is the decision to terminate treatment made? (When? Goals achieved, economic issue, etc.)

2. I'm assuming you rely on intuitive judgment a great deal. How does this effect decisions made during the treatment process?

Research \& Evaluation

1. Have you been involved in any research projects concerning evaluation issues? If yes:

A. How does this experience relate to your current practice?

B. Has this experience caused you to use any specific evaluation techniques (data gathering and analysis)? 
2. Do you read research articles?

A. Do you use this information in your practice? How?

B. Have you published any related articles?

3. What problems do you encounter in the evaluation of your practice?

\section{Professional Growth}

1. Are you involved in consultation with other professionals or agencies? If yes:
A. In giving--
B. In receiving--
C. Can you verbalize how this might influence your evaluation process?

2. A. How often do you attend workshops, seminars, and conferences?

B. How does the information you gather there impact on your private practice? 
Portland State University

School of Social Work

January 1,1980

Mary Doe

Phone: 222-2222

000 Drive

Portland, OR

Dear Mary Doe:

We would like to thank you for agreeing to cooperate with us in our research project. The purpose of this research is to collect information from local private clinicians concerning the extent to which evaluation is a part of their practice.

To confirm our phone conversation, the forty-five (45) minute interview is scheduled for 12 noon (sharp) on Tuesday, January 15, at S.W. Main, Portland, oregon. The interviewer who will be meeting with you is

A summary of the research will be mailed to you upon completion of the project in April of 1980 .

If you have any questions regarding the interview, please feel free to call Elliot Geller at 222-5342. Thank you very much.

\section{Sincerely,}

Daniel R. Brophy

Interview Coordinator

Elliot M. Geller

Interview Coordinator

Nancy M. Koroloff, Faculty Advisor

Daniel R. Brophy

Elliot M. Geller

Stephan I. Grove

Nancy E. Hedrick

A. Jill Nelson

Babette A. Vanelli 